\title{
The PAAFID Project: Exploring the Perspectives of Autism in Adult Females among Intellectual
}

\section{Disability Healthcare Professionals}

\author{
Samuel Tromans, Verity Chester, Chaya Kapugama, Amy Elliot, Sarah Robertson and Mary Barrett
}

\begin{abstract}
Authors Affiliations
Samuel Tromans is a Specialist Registrar in Intellectual Disability Psychiatry at Leicestershire Partnership NHS Trust, Leicester, UK, and an Honorary Academic Clinical Lecturer at the Department of Health Sciences, University of Leicester, Leicester, UK.

Verity Chester is a Research Associate at the Priory Group, Norwich, Norfolk, UK and a PhD Candidate at Norwich Medical School, University of East Anglia, Norwich, UK.

Chaya Kapugama is a Specialist Registrar in Intellectual Disability Psychiatry at Leicestershire Partnership NHS Trust, Leicester, UK.

Amy Elliot is a Foundation Year Doctor at University Hospitals of Leicester, Leicester, UK.

Sarah Robertson is an Enhanced Assessment and Treatment Practitioner at Hertfordshire Partnership University NHS Foundation Trust, UK.

Mary Barrett is a Consultant in Intellectual Disability Psychiatry at Leicestershire Partnership NHS Trust, Leicester, UK, and Training Programme Director at Health Education England East Midlands, Leicester, UK.
\end{abstract}

\begin{abstract}
Purpose: This project aimed to explore the perspectives of healthcare professionals on autism in adult females with intellectual disability, including regarding the gender ratio of autism, the clinical manifestation of autism in females, and the recognition, screening and diagnosis of autism.

Design/ methodology/ approach: The questionnaire was developed following a review of the relevant literature and distributed to professionals within three healthcare trusts as well as members of two clinical research groups. The questionnaire was completed by 80 intellectual disability healthcare professionals. Data was aggregated and analysed using Microsoft Excel.

Findings: Intellectual disability healthcare professionals had a lack of recognition of the smaller gender ratio of autism in patients with intellectual disabilities, as compared to those without. Most respondents believe that autism manifests differently in females; with women demonstrating a greater ability to mask their symptoms. A considerable proportion of participants reported feeling less confident in recognising, screening, and diagnosing autism in female patients, with many endorsing a wish for additional training in this area.
\end{abstract}


Practical implications: These findings suggest that intellectual disability healthcare professionals are keen to improve their skills in providing services for women with autism. Training programmes at all levels should incorporate the specific needs of women with ASD, and individual professionals and services should actively seek to address these training needs in order to promote best practice and better outcomes for women with autism.

Originality/ value: This is the first published questionnaire exploring the perspectives of healthcare professionals regarding autism in adult females with intellectual disability.

Keywords: Women, Girls, Gender differences, Learning disability, Pervasive developmental disorder, Neurodevelopmental disorder

Type: Research paper 


\section{Introduction}

Autism is a lifelong neurodevelopmental condition characterised by a triad of impairments in reciprocal social interaction and communication, as well as restricted, repetitive and stereotyped behaviours (World Health Organization, 1992). Whilst originating in childhood, autism follows a persistent lifelong course, extending into adulthood and old age (Howlin, 2000). A wide variety of therapeutic interventions for autism have been studied, including behavioural, psychological and medication-based approaches (Tromans and Adams, 2018); whilst these can improve the quality of life for patients and carers, significant difficulties usually remain (Newschaffer et al., 2007).

Autism is strongly associated with intellectual disability (ID), defined by DSM-5 (American Psychiatric Association, 2013) as a disorder involving deficits of both intellectual and adaptive functioning, with onset during the developmental period (i.e. the first 18 years of life). Brugha et al. (2016), in a large study of 7,274 adults with different levels of intellectual ability, found an overall study population prevalence estimate of $1.1 \%$ (95\% CI 0.3-1.9) for autism. However, when analysing subgroups, they found that individuals with moderate-profound ID had markedly increased rates of autism, with a prevalence of $42.3 \%$ (95\% CI 31.1 -54.3) and 35.2\% (95\% CI 23.5-49.0) in males and females respectively. For this reason, the knowledge and views of ID healthcare professionals are particularly pertinent to the provision of care for individuals with autism.

Historically, autism has been considered as a condition predominantly affecting males, as with other neurodevelopmental disorders, such as attention deficit hyperactivity disorder and ID (Werling and Geschwind, 2013). A recent meta-analysis of autism prevalence in child studies by Loomes et al. (2017) found an overall male to female odds ratio of 4.20 (95\% CI 3.84-4.60) across all eligible studies, though this ratio reduces to 3.32 (95\% CI 2.88-3.84) when only studies of high methodological quality were considered. The academic literature largely focuses on the presentation of autism in men, with less information on the clinical profile in women (Kirkovski et al., 2013). From the first published descriptions of autism, it has been a male-typical disorder: 8 of the 11 cases described by Kanner, and all 4 cases described by Asperger, were male (Werling and Geschwind, 2013). Indeed, in some studies, researchers opt to only recruit male participants, potentially reinforcing a gender bias with regard to our understanding of autism (Lai et al., 2015). Similarly, many of the diagnostic tools for autism were validated in predominantly male study populations, suggesting that there may be a gender bias inherent to the diagnostic process (Werling and Geschwind, 2013). The idea of autism being more prevalent in 
males has been further supported by the extreme male brain theory of autism (Baron-Cohen, 2002), which suggests that autism represents a more extreme manifestation of the general tendency of male brains to be more adept at systematizing, and less so at empathizing, relative to female brains, though such difference could be, at least in part, socially constructed (Baron-Cohen et al., 2005a). These factors have led to the diagnostic conceptualisation of autism being largely based on men.

However, in recent years the notion of autism as a 'male condition' has been challenged, with many suspecting that autism is underdiagnosed, under recognised, and overlooked in female patients (Ferri et al., 2018). Increasing numbers of females with autism are now being identified. While the exact reasons for this are unclear, it is likely to be due to a combination of factors, including increasing public awareness of autism in general, higher numbers of women seeking diagnosis (often following receiving a diagnosis for their child), and increasing awareness of the female autistic phenotype among clinicians. Indeed, a systematic review and metaanalysis by Van Wijngaarden-Cremers et al. (2014) supports the assertion that there may be phenotypic differences between male and females with autism, particularly in older age groups. For example, the authors found that boys showed more repetitive and stereotyped behaviours than females, but only from the age of six years. Holtmann et al. (2007) similarly suggested a difference in the cognitive phenotype of autism between sexes, observing no marked sex differences in the core triad of autistic impairments, but noting that parent reports demonstrated significantly more symptoms in females, especially with regard to social, attention and thought problems.

Lai et al. (2011) also found that the severity of childhood core autism symptoms did not differ between the sexes. Males and females also did not differ in self-reported empathy, systemizing, anxiety, depression, and obsessive-compulsive traits/symptoms or mentalizing performance. However, adult females showed more lifetime sensory symptoms, and more self-reported autistic traits than males. While women reported fewer current socio-communication difficulties, the authors discussed this in the context of female participants being more motivated, and thus putting increased effort into developing compensatory skills that help them to appear "socially typical", and the ability to "camouflage" their autism, involving conscious, observational learning of how to act in a social setting, adopting social roles and following social scripts. Indeed, a subsequent study by Lai and colleagues (2017) attempted to quantitatively measure camouflaging as the discrepancy between an individual's external presentation, as measured by their Autism Diagnostic Observation Schedule (Lord et al., 2000) findings, and their internal status, measured by the Autism Spectrum Quotient (Baron-Cohen et al., 2001) and Reading the Mind in the Eyes Test (Baron-Cohen et al., 1997) results. They found that whilst women with 
autism generally had higher camouflaging scores than their male counterparts, significant within-group variability was observed. Dean et al. (2017) suggest that the female social landscape supports the camouflage hypothesis; girls with autism spectrum disorder used compensatory behaviours, such as staying in close proximity to peers and weaving in and out of activities, which appeared to mask their social challenges. However, females with autism are still, on average, diagnosed at a later age than males (Lai and Baron-Cohen, 2015), which impacts on their ability to derive timely benefit from supportive services (Daniels and Mandell, 2014).

Additionally, the lives of females with autism have been detailed in works of literature. Autobiographical accounts, such as those of Temple Grandin (1996), describe an urge to communicate and share their atypical sensory and emotional experiences with others, in a way not traditionally associated with autism (Davidson, 2007). Additionally, there are examples in works of fiction of females with autism describing their experiences of the condition, such as Corinne Duyvis in On the Edge of Gone (2016), as well as non-autistic authors drawing upon their knowledge of caring for a female with autism, such as Kathryn Erskine in Mockingbird (2010). Such writing can challenge myths and stereotypes about autism in females, and help combat stigma (Tharian et al., in press).

Due to such differences, women with ASD have faced numerous barriers to diagnosis, such as being misdiagnosed with other forms of mental disorder, such as social phobia and borderline personality disorder (Attwood, 2007), and experiencing superficial generalisations, such as the belief that a woman who can make eye contact or be married cannot have autism (Lai and Baron-Cohen, 2015). Current internationally agreed diagnostic criteria do not give examples of the types of difficulties experienced by girls and women, and how these can contribute to them presenting differently to clinicians. This could lead to diagnosticians perceiving someone who superficially appears able, demonstrates an ability to engage in reciprocal conversation and uses appropriate affect and gestures as not satisfying such criteria (Gould and Ashton-Smith, 2011).

The National Institute for Health and Care Excellence (NICE) guidance on autism in adults (2012) specifically recommends the use of the Autism Diagnostic Observation Schedule - Generic (ADOS-G) (Lord et al., 2000) and Autism Diagnostic Interview - Revised (ADI-R) (Lord et al., 1994) as formal assessment tools for people with ID. For screening, they recommend the 10 item version of the Autism Spectrum Quotient (AQ10) (Allison et al., 2012), though only for individuals with mild ID. However, guidance pertaining to the use of these instruments with women is lacking. 
The gender ratio for autism is also affected by the presence of ID, with rates of 4.5:1 (male: female) typically reported for those without ID (Fombonne, 2009), in contrast to 1-2:1 for individuals with ID, in both child and adolescents (Mattila et al., 2011) and adult populations (Brugha et al., 2016). Kirkovski and colleagues (2013) suggested that such a difference may be due to autism in lower-functioning females manifesting clinically more similarly to their male counterparts, whereas autism presents differently in higher functioning females, leading to them being undiagnosed or misdiagnosed. Given the high prevalence of autism in people with ID, there is a clear need for a substantial proportion of the workforce to have appropriate training in screening and diagnosis. A literature review by Werner and Stawski (2012) emphasised the importance of improving the knowledge, competence and attitudes of ID healthcare professionals with regards to working with patients with dual diagnosis (i.e. the coexistence of ID and a mental disorder, such as autism). It is also essential that ID healthcare professionals are as confident in their practice with women as with men. In order to improve these areas, it is imperative we first understand the perspectives of ID healthcare professionals of their own competencies in working with this population.

Aims

The primary aim of this study was to explore the perspectives of ID healthcare professionals regarding autism in adult females. The secondary aim was to collect information pertaining to their perceived autismrelated training needs.

\section{Method}

\section{Questionnaire}

The Perspectives of Autism in Adult Females among ID healthcare professionals Questionnaire (PAAFID-Q) was designed to be a short, user friendly questionnaire, using language that ID healthcare professionals from all disciplines would readily understand. It is available for use on request from the lead author. Questions were based on a review of the literature on females with autism, as well as the other aforementioned related topics pertaining to care provision for individuals with autism within ID mental health services. The questions were grouped into four main domains according to the main research questions: 
- Gender ratio of autism: both in patients with ID and those without ID (non-ID)

- Clinical manifestation of autism in females

- Recognition, screening and diagnosis of autism in females

- $\quad$ Training needs pertaining to autism

With regards to the response format, most questions (e.g. pertaining to ratios, frequencies and levels of confidence) had a multiple choice response format, where options were made available for participants to select. However, some questions had an 'other' option available, so that participants could provide a free-text answer of their own choosing.

\section{Procedure}

The PAAFID-Q was made available for completion between the dates of $9^{\text {th }}$ July to $3^{\text {rd }}$ August 2018. Invitations were sent out via email, with a link to complete the questionnaire online; two subsequent reminder emails were later sent during the time period where the questionnaire was available for completion.

Additionally, in the case of the two NHS healthcare trusts and independent sector specialized inpatient service, paper copies of the questionnaires were made available for completion, for individuals who preferred this option to navigating an online form.

\section{Participants}

The PAAFID-Q was distributed to all ID healthcare professionals working within two NHS healthcare trusts (Leicestershire Partnership NHS Trust and Hertfordshire Partnership University NHS Foundation Trust) and an independent sector specialised inpatient service (St Johns House, Norfolk) as well as to the members of three groups of ID healthcare professionals (The Clinical Research Group in Forensic Intellectual and Developmental Disabilities, the Intellectual Disability Research UK mailing list, and the UK Health and Learning Disabilities Network). All participating individuals are ID healthcare professionals currently working in the United Kingdom.

Table 1 summarizes the characteristics of the questionnaire respondents. Of the 80 ID healthcare professionals, $76 \%(n=61)$ were female. Nursing was the most represented professional role, with $39 \%(n=31)$ 
of respondents belonging to this professional group. Other groups representing significant proportions of respondents included psychiatrists $(20 \%, \mathrm{n}=16)$, psychologists $(18 \%, \mathrm{n}=14)$ and speech and language therapists $(9 \%, n=7)$. Twelve (15\%) respondents described their role as "other", (see Table 1 for a full breakdown). The proportions working in different work settings was fairly evenly divided, with $41 \%(\mathrm{n}=33)$ based in the community, 35\% $(n=28)$ based in an inpatient setting, and 24\% $(n=19)$ being based in both of these settings as part of their professional role.

\section{Ethics}

As the study utilised a survey methodology, it did not require ethical approval under the UK policy framework for health and social care research (Health Research Authority, 2017).

\section{Findings}

\section{Gender ratios}

Table 2 details the survey respondents' perspectives on gender ratios in autism, in both those with and without ID, as well as the clinical manifestation of autism in females. In adults with ID, $66 \%(n=53)$ of survey respondents believed autism to be more prevalent in males, with $45 \%(n=36)$ estimating the ratio as $1: 2-4$ and $21 \%(n=17)$ estimating autism to be over 4 times as prevalent in adult males with ID. The main reason for their views on this topic was clinical experience, with $63 \%(n=50)$ citing this as the reason for their view. With regard to adults without ID (non-ID), broadly similar findings were found, with 54\% $(n=43)$ of respondents believing autism to be more prevalent in males.

\section{Clinical manifestation of autism in females}

The vast majority of respondents $(85 \% ; n=68)$ viewed autism as manifesting differently in females compared to males. The main reason for believing this to be the case is due to an ability to mask their symptoms, with $40 \%(n=32)$ of respondents citing this as the primary reason for said differences. Participants 
also cited gender-related social expectations, differences in the rates of other mental disorders (such as comorbid personality disorder, depression and anxiety), as well as differences in other domains, such as social interaction, emotional and social maturity, communication, and coping skills.

\section{Recognition, screening and diagnosis}

Table 3 details responses related to the recognition, screening and diagnosis of autism. Of the respondent population, $78 \%(\mathrm{n}=62)$ are involved in the recognition of patients with possible autism in their own practice. Of these, $23 \%(n=14)$ consider themselves 'very confident' and $65 \%(n=40)$ 'somewhat confident' with regard to such recognition, with $11 \%(n=7)$ rating themselves as 'neither confident nor unconfident and $2 \%$ $(\mathrm{n}=1)$ as 'somewhat unconfident'. Of the 62 individuals involved in the recognition of patients with autism, $48 \%$ $(n=30)$ reported feeling less confident with regards to recognising the condition in female patients.

With regards to the screening of patients with possible autism, 39\% $(n=31)$ of respondents are involved in this process in their own practice. Of the various screening tools available, the Autism Quotient (AQ) is most widely used among the respondent population, with 55\% of those involved in screening using this tool. As would perhaps be expected, the vast majority of respondents involved in autism screening $(81 \%, n=25)$ incorporate clinical judgment into their screening decision process. Out of those respondents involved in screening, $90 \%(n=28)$ feel either somewhat $(71 \%, n=22)$ or very confident $(19 \%, n=6)$ in screening for autism in one of their patients. However, as with recognition of autism, a sizeable proportion $(43 \%, \mathrm{n}=13)$ feel less confident in screening for autism in one of their female patients.

In terms of full autism diagnostic assessments, $21 \%(n=17)$ of respondents conduct these in their own clinical practice. The majority of those respondents conducting full autism diagnostic assessments typically conduct at least one assessment every three months $(71 \% ; n=12)$. Of the respondent population, $33 \%(n=26)$ have received formal training for autism diagnosis. Of those who have received formal autism diagnostic training, the most frequent responses were for the Autism Diagnostic Observation Schedule [ADOS] (62\%, $n=16)$, Autism Diagnostic Interview - Revised [ADI-R] $(35 \%, n=9)$ and the Diagnostic Interview for Social and Communication Disorders [DISCO] $(27 \%, n=7)$. Respondents involved in full autism diagnostic assessments generally reported confidence in doing so, with $88 \%(\mathrm{n}=15)$ rating their confidence as either somewhat $(53 \%$, $n=9)$ or very confident $(35 \%, n=6)$. 


\section{Training needs}

Table 4 outlines respondents' views pertaining to their autism-related training needs. Out of the respondent population, $76 \%(\mathrm{n}=61)$ feel that they have additional training needs pertaining to care provision for patients with autism. In terms of these training needs, interventions for autism $(16 \%, n=10)$, sensory needs $(16 \%, n=10)$, identification and diagnosis $(13 \%, n=8)$ and gender differences in autism $(11 \%, n=7)$ were the most popular responses.

\section{Discussion}

This project has examined the views of ID healthcare professionals regarding several issues pertaining to autism in females, namely the gender ratio, differences in clinical manifestation and recognition, screening and diagnosis. Additionally, one non-gender specific domain was explored - the views of ID healthcare professionals regarding their training needs relating to autism.

Interestingly, a higher proportion of the respondent population viewed the autism gender ratio as favouring males over females in patients with ID $(66 \%, n=53)$ relative to in non-ID patients $(n=43,54 \%)$. However, the main reason for this difference in responses is that a higher proportion of respondents selected 'unsure' for this question in the non-ID group relative to the ID group (30\% vs $18 \%$ ); when individuals responding as 'unsure' are excluded from the analysis, views on the gender ratio are roughly equivalent (i.e. $53 / 66[80 \%]$ of respondents view autism as being more prevalent in males with ID relative to females with ID, and 43/54 [80\%] of respondents view autism as being more prevalent in non-ID males relative to non-ID females). Therefore, the seemingly different response profiles for the autism gender ratio question in ID vs. nonID groups is largely explained by the higher levels of uncertainty pertaining to the gender ratio in non-ID patients, which makes logical sense considering the study population are healthcare professionals specialised in working with patients with ID. However, the respondent views on the autism gender ratio nevertheless do not appear to reflect the research literature, which indicates that autism is more equally distributed between genders among those with ID (Mattila et al., 2011, Brugha et al., 2016). This finding could be partially attributable to most responders reporting clinical experience as being the main reason for their estimate of the autism gender ratio in patients with ID $(63 \%, n=50)$, as opposed to appraisal of the research evidence $(26 \%, n=21)$. These 
findings suggest that there is a clear discrepancy between the autism gender ratio reported in prevalence studies and the views of healthcare professionals involved in routine clinical practice.

Most responders viewed autism as manifesting differently in females compared to their male counterparts $(85 \%, n=68)$. The most commonly cited main reason for this was an ability to mask their symptoms $(40 \%, \mathrm{n}=32)$. This view is supported by research evidence, with studies on children, adolescents (Mandy et al., 2012) and adults with autism (Lai et al., 2011) reporting increased rates of functional social behaviour in females. Indeed, females with autism may be less readily identified owing to an ability to consciously mask or camouflage their autism symptoms; a strategy which whilst having some potential benefits, can conversely require a high degree of effort to maintain, leading to significant anxiety and stress (Lai et al., 2011).

Whilst many ID healthcare professionals viewed themselves as being involved in the recognition of autism in their practice $(78 \%, \mathrm{n}=62)$, a much smaller proportion take part in formal screening for the condition $(39 \%, n=31)$. Further work to establish the subsequent processes that bridge the gap between recognition and screening may be helpful in establishing the proportion of patients recognised as having possible autism who are subsequently subjected to more formal screening. Indeed, there may be a need for more ID healthcare professionals to be trained in the use of autism screening tools, though it is important that such tools are appropriate for the ID population. For example, NICE do not recommend use of the AQ in individuals with moderate to severe ID (National Institute for Health and Care Excellence, 2012). With regard to both the recognition and screening of autism, it is noteworthy that while most ID healthcare professionals report being somewhat or very confident in general (recognition: $87 \%, n=54$; screening: $90 \%, n=28$ ), a lower degree of confidence was reported for recognising and screening female patients in many respondents (recognition: $48 \%$, $n=30$; screening: $43 \%, n=13$ ). However, the relationship between healthcare professional confidence in screening and accuracy (in terms of predicting a resulting diagnosis of autism) is a complex one. A study conducted by Hedley et al. (2016) reported only a small positive confidence-accuracy relationship in screening for autism in child patients.

Interestingly, more respondents have received formal training for autism diagnosis $(33 \%, \mathrm{n}=26)$ than those who conduct such assessments in their current clinical practice $(21 \%, n=17)$. Given the unacceptable waiting list times for autism assessments cited by patients and carers (Pellicano et al., 2014, Crane et al., 2016), there is a need for further work to establish whether this finding is more widely present among healthcare professionals, and if so, the reasons for individuals trained in autism diagnosis not conducting such assessments 
in their own clinical practice. Reassuringly, of those healthcare professionals who have received formal diagnostic training, most have been trained in tools recommended in the NICE guidance for autism spectrum disorder in adults with ID; 32 of the 39 instances of formal diagnostic training reported were in using the ADOS, ADI-R and DISCO (National Institute for Health and Care Excellence, 2012). In some instances, individuals reported receiving multiple forms of formal autism diagnostic training.

Relatedly, the majority of the respondents $(76 \%, \mathrm{n}=61)$ reported that they have autism-related training needs. Ideally, this training should be incorporated within professional training programmes (such as nursing, psychological and medicine programmes) as well as being offered by service providers, in order to promote awareness of the presentation and needs of women with autism among staff at various stages of their professional development. Based on the most frequently cited perceived main training needs within our dataset, areas of focus for such training could include interventions for autism $(n=10)$, sensory needs $(n=10)$, identification and diagnosis $(n=8)$ and gender differences $(n=7)$. However, given the relatively small sample size for the study $(n=80)$, further research could help better ascertain the perceived training needs of ID health professionals, as well as whether these perceived needs are in keeping with those suggested for them by patients with autism and their carers. Training may also take the form of conferences, teaching sessions, or online modules on this topic. Individual professionals and services should actively seek to address these training needs in order to promote best practice and better outcomes for women with autism.

Our study has several limitations. Firstly, the questionnaire offered limited opportunities for qualitative free text responses for the responder, who may have wished to provide further contextual information. Secondly, this study only includes the views of ID healthcare professionals, rather than patients and their carers, and if such groups were also included, they may potentially have different viewpoints. A note of caution should be considered regarding the generalisation of these findings. A high proportion of respondents were based in one setting, which may be partially attributable to more of the authors being based at this service. The vast majority of respondents were themselves female (76\%), though this mirrors the gender distribution of the National Health Service workforce (NHS Employers, 2017). Nursing staff represented a high proportion of the respondent population $(39 \%)$, which is also likely to be reflective of this staff group representing a similarly high proportion of the ID healthcare professional workforce. A further drawback relates to asking professionals about their perceived competency in their role, which may increase the likelihood of desirable responding (Chester et al., 2017). Finally, though not within the originally intended scope of this study, the relative lack of male 
respondents $(n=19)$ prevented meaningful subgroup comparison between the responses of male and female ID health professionals. Exploring this topic in greater depth would represent an interesting area of future research.

Exploring the views of autism among ID healthcare professionals, both in general and females specifically, is important in helping us establishing their views in comparison to the research evidence base, their training needs and their confidence in recognising and diagnosing this condition, which is particularly prevalent in individuals with ID. The PAAFID-Q proved to be a useful instrument in ascertaining these views among a diverse group of health professionals. Future research will seek to further develop this instrument, and explore its utility in evaluating baseline perspectives, and its sensitivity to assessing change following interventions, such as pre- and post- training on women and autism. Further research with a more qualitative focus, such as interviewing ID healthcare professionals, as well as ascertaining the views of females with autism, could help further improve understanding of these complex, important issues.

\section{References}

Allison, C., Auyeung, B. and Baron-Cohen, S. (2012), "Toward brief "Red Flags" for autism screening: The Short Autism Spectrum Quotient and the Short Quantitative Checklist for Autism in toddlers in 1,000 cases and 3,000 controls", Journal of the American Academy of Child and Adolescent Psychiatry, Vol. 51, No. 2, pp. 202-212.

American Psychiatric Association (2013), Diagnostic and statistical manual of mental disorders: DSM-5, American Psychiatric Publishing, Arlington, Virginia.

Baron-Cohen, S., Wheelwright, S. and Jolliffe, A.T. (1997), "Is there a" language of the eyes"? Evidence from normal adults, and adults with autism or Asperger syndrome", Visual cognition, Vol. 4, No. 3, pp.311-331.

Baron-Cohen, S. (2002), "The extreme male brain theory of autism", Trends in cognitive sciences, Vol. 6, No. 6, pp. $248-254$.

Baron-Cohen, S., Knickmeyer, R.C. and Belmonte, M.K. (2005a), "Sex differences in the brain: implications for explaining autism", Science, Vol. 310, No. 5749, pp. 819-823.

Baron-Cohen, S., Wheelwright, S., Robinson, J. and Woodbury-Smith, M. (2005b), "The adult Asperger assessment (AAA): a diagnostic method", Journal of Autism and Developmental Disorders, Vol. 35, No. 6, pp. 807.

Baron-Cohen, S., Wheelwright, S., Skinner, R., Martin, J. and Clubley, E. (2001), "The autism-spectrum quotient (AQ): Evidence from Asperger syndrome/high-functioning autism, males and females, scientists and mathematicians", Journal of Autism and Developmental Disorders, Vol. 31, No. 1, pp. 5-17.

Brugha, T.S., Spiers, N., Bankart, J., Cooper, S.A., McManus, S., Scott, F.J., Smith, J. and Tyrer, F. (2016), "Epidemiology of autism in adults across age groups and ability levels", The British journal of psychiatry, Vol. 209, No. 6, pp. 498-503. 
Chester, V., Alexander, R.T. and Morgan, W. (2017), "Measuring relational security in forensic mental health services", BJPsych bulletin, Vol. 41, No. 6, pp. 358-363.

Constantino, J.N. and Gruber, C.P. (2012), Social responsiveness scale (SRS), Western Psychological Services Torrance, California.

Crane, L., Chester, J.W., Goddard, L., Henry, L.A. and Hill, E. (2016), "Experiences of autism diagnosis: A survey of over 1000 parents in the United Kingdom", Autism, Vol. 20, No. 2, pp. 153-162.

Daniels, A.M. and Mandell, D.S. (2014), "Explaining differences in age at autism spectrum disorder diagnosis: A critical review", Autism, Vol. 18, No. 5, pp. 583-597.

Davidson, J. (2007), "'In a World of her Own...': Re-presenting alienation and emotion in the lives and writings of women with autism", Gender, Place and Culture, Vol. 14, No. 6, pp. 659-677.

Dean, M., Harwood, R. and Kasari, C. (2017), "The art of camouflage: Gender differences in the social behaviors of girls and boys with autism spectrum disorder", Autism, Vol. 21, No. 6, pp. 678-689.

Duyvis, C. (2016), On the Edge of Gone, Amulet Books, New York, NY.

Erskine, K. (2010), Mockingbird, Usborne Publishing, London, UK.

Ferri, S.L., Abel, T. and Brodkin, E.S. (2018), "Sex differences in autism spectrum disorder: a review", Current psychiatry reports, Vol. 20, No. 2, pp. 9.

Fombonne, E. (2009), "Epidemiology of pervasive developmental disorders", Pediatric research, Vol. 65, No. 6, pp. 591-598.

Gillberg, C., Gillberg, C., Råstam, M. and Wentz, E. (2001), "The Asperger Syndrome (and high-functioning autism) Diagnostic Interview (ASDI): a preliminary study of a new structured clinical interview", Autism, Vol. 5, No. 1, pp. 57-66.

Gould, J. and Ashton-Smith, J. (2011), "Missed diagnosis or misdiagnosis? Girls and women on the autism spectrum", Good Autism Practice, Vol. 12, No. 1, pp. 34-41.

Grandin, T. (1996), Thinking in Pictures: And Other Reports from My Life with Autism, Vintage Books, New York, NY.

Health Research Authority (2017), "UK Policy Framework for Health and Social Care Research", available at: https:/www.hra.nhs.uk/planning-and-improving-research/policies-standards-legislation/uk-policyframework-health-social-care-research/ (accessed 5 September 2018).

Hedley, D., Brewer, N., Nevill, R., Uljarević, M., Butter, E. and Mulick, J.A. (2016), "The relationship between clinicians' confidence and accuracy, and the influence of child characteristics, in the screening of autism spectrum disorder", Journal of Autism and Developmental Disorders, Vol. 46, No. 7, pp. 2340-2348.

Holtmann, M., Bölte, S. and Poustka, F., (2007), "Autism spectrum disorders: Sex differences in autistic behaviour domains and coexisting psychopathology", Developmental Medicine \& Child Neurology, Vol. 49, No. 5, pp.361-366.

Howlin, P. (2000), "Outcome in adult life for more able individuals with autism or Asperger syndrome", Autism, Vol. 4, No. 1, pp. 63-83.

Kirkovski, M., Enticott, P.G. and Fitzgerald, P.B. (2013), "A review of the role of female gender in autism spectrum disorders", Journal of Autism and Developmental Disorders, Vol. 43, No. 11, pp. 2584-2603. 
Lai, M. and Baron-Cohen, S. (2015), "Identifying the lost generation of adults with autism spectrum conditions", The Lancet Psychiatry, Vol. 2, No. 11, pp. 1013-1027.

Lai, M., Lombardo, M.V., Auyeung, B., Chakrabarti, B. and Baron-Cohen, S. (2015), "Sex/gender differences and autism: setting the scene for future research", Journal of the American Academy of Child \& Adolescent Psychiatry, Vol. 54, No. 1, pp. 11-24.

Lai, M.C., Lombardo, M.V., Ruigrok, A.N., Chakrabarti, B., Auyeung, B., Szatmari, P., Happé, F., BaronCohen, S. and MRC AIMS Consortium (2017), "Quantifying and exploring camouflaging in men and women with autism", Autism, Vol. 21, No. 6, pp. 690-702.

Lai, M., Lombardo, M.V., Pasco, G., Ruigrok, A.N., Wheelwright, S.J., Sadek, S.A., Chakrabarti, B., BaronCohen, S. and MRC AIMS Consortium (2011), "A behavioral comparison of male and female adults with high functioning autism spectrum conditions", PloS one, Vol. 6, No. 6, pp. e20835.

Loomes, R., Hull, L. and Mandy, W.P.L. (2017), "What Is the Male-to-Female Ratio in Autism Spectrum Disorder? A Systematic Review and Meta-Analysis", Journal of the American Academy of Child and Adolescent Psychiatry, Vol. 56, No. 6, pp. 466-474.

Lord, C., Risi, S., Lambrecht, L., Cook, E.H., Leventhal, B.L., DiLavore, P.C., Pickles, A. and Rutter, M. (2000), "The Autism Diagnostic Observation Schedule - Generic: A standard measure of social and communication deficits associated with the spectrum of autism", Journal of Autism and Developmental Disorders, Vol. 30, No. 3, pp. 205-223.

Lord, C., Rutter, M. and Le Couteur, A. (1994), "Autism Diagnostic Interview-Revised: a revised version of a diagnostic interview for caregivers of individuals with possible pervasive developmental disorders", Journal of Autism and Developmental Disorders, Vol. 24, No. 5, pp. 659-685.

Mandy, W., Chilvers, R., Chowdhury, U., Salter, G., Seigal, A. and Skuse, D. (2012), "Sex differences in autism spectrum disorder: evidence from a large sample of children and adolescents", Journal of Autism and Developmental Disorders, Vol. 42, No. 7, pp. 1304-1313.

Mattila, M., Kielinen, M., Linna, S., Jussila, K., Ebeling, H., Bloigu, R., Joseph, R.M. and Moilanen, I. (2011), "Autism spectrum disorders according to DSM-IV-TR and comparison with DSM-5 draft criteria: an epidemiological study", Journal of the American Academy of Child \& Adolescent Psychiatry, Vol. 50, No. 6, pp. 583-592.

National Institute for Health and Care Excellence (2012), "Autism spectrum disorder in adults: diagnosis and management. NICE guideline [CG142]", available at: https://www.nice.org.uk/guidance/cg142 (accessed 5 September 2018).

Newschaffer, C.J., Croen, L.A., Daniels, J., Giarelli, E., Grether, J.K., Levy, S.E., Mandell, D.S., Miller, L.A., Pinto-Martin, J. and Reaven, J. (2007), "The epidemiology of autism spectrum disorders", Annu.Rev.Public Health, Vol. 28, pp. 235-258.

NHS Employers (2017), "Gender in the NHS", available at: https://www.nhsemployers.org//media/Employers/Publications/Gender-in-the-NHS.pdf (accessed 5 September 2018).

Pellicano, E., Dinsmore, A. and Charman, T. (2014), "What should autism research focus upon? Community views and priorities from the United Kingdom", Autism, Vol. 18, No. 7, pp. 756-770.

Ritvo, R.A., Ritvo, E.R., Guthrie, D., Ritvo, M.J., Hufnagel, D.H., McMahon, W., Tonge, B., Mataix-Cols, D., Jassi, A. and Attwood, T. (2011), "The Ritvo Autism Asperger Diagnostic Scale-Revised (RAADS-R): a scale to assist the diagnosis of autism spectrum disorder in adults: an international validation study", Journal of Autism and Developmental Disorders, Vol. 41, No. 8, pp. 1076-1089. 
Tharian, P., Henderson, S., Wathanasin, N., Hayden, N., Chester, V. and Tromans, S. (in press), "Characters with autism spectrum disorder in fiction: Where are the women and girls?", Advances in Autism.

Tromans, S. and Adams, C. (2018), "Brief report: Autism spectrum disorder: A comprehensive survey of randomized controlled trials", Journal of Autism and Developmental Disorders, Vol. 48, No. 9, pp. 1-5.

Van Wijngaarden-Cremers, P.J., van Eeten, E., Groen, W.B., Van Deurzen, P.A., Oosterling, I.J. and Van der Gaag, Rutger Jan (2014), "Gender and age differences in the core triad of impairments in autism spectrum disorders: a systematic review and meta-analysis", Journal of Autism and Developmental Disorders, Vol. 44 , No. 3, pp. 627-635.

Werling, D.M. and Geschwind, D.H. (2013), "Sex differences in autism spectrum disorders", Current opinion in neurology, Vol. 26, No. 2, pp. 146-153.

Werner, S. and Stawski, M. (2012), "Mental health: Knowledge, attitudes and training of professionals on dual diagnosis of intellectual disability and psychiatric disorder", Journal of Intellectual Disability Research, Vol. 56, No. 3, pp. 291-304.

Wing, L., Leekam, S.R., Libby, S.J., Gould, J. and Larcombe, M. (2002), The diagnostic interview for social and communication disorders: Background, inter-rater reliability and clinical use. Journal of Child Psychology and Psychiatry, Vol. 43, No. 3, pp. 307-325.

World Health Organization (1992), The ICD-10 classification of mental and behavioural disorders: clinical descriptions and diagnostic guidelines, World Health Organization, Geneva. 
Table 1: Respondent characteristics

\begin{tabular}{|lcc|}
\hline Variable & $\boldsymbol{n}$ & $\mathbf{\%}$ \\
\hline Gender & 19 & $24 \%$ \\
Male & 1 & $76 \%$ \\
Female & & \\
Healthcare Trust & 29 & $36 \%$ \\
Leicestershire Partnership NHS Trust & 13 & $16 \%$ \\
Hertfordshire Partnership University NHS Foundation Trust & 10 & $13 \%$ \\
Priory Group (Norfolk) & 28 & $35 \%$ \\
Other ${ }^{1}$ & & \\
Professional role & 31 & $39 \%$ \\
Nursing & 26 & $33 \%$ \\
Qualified Nurse & 3 & $4 \%$ \\
Student Nurse & 2 & $3 \%$ \\
Nursing Assistant & 16 & $20 \%$ \\
Psychiatrist & 15 & $19 \%$ \\
Consultant Psychiatrist & 1 & $1 \%$ \\
Psychiatry Trainee & 14 & $18 \%$ \\
Psychology & 12 & $15 \%$ \\
Qualified Psychologist & 1 & $1 \%$ \\
Assistant Psychologist & 1 & $1 \%$ \\
Student Psychologist & 7 & $9 \%$ \\
Speech and Language Therapy & 12 & $15 \%$ \\
Other Professional Roles & 1 & $1 \%$ \\
Administrative & 1 & $1 \%$ \\
Academic & 4 & $5 \%$ \\
Managerial & 3 & $4 \%$ \\
Occupational therapist & 2 & $3 \%$ \\
Physiotherapy & 1 & $1 \%$ \\
Social worker & & \\
Work Setting & 33 & $35 \%$ \\
Community-based & 28 & $24 \%$ \\
Inpatient-based & 19 & \\
Based in both community and inpatient settings & & \\
& & \\
& & \\
\end{tabular}

\footnotetext{
1 'Other' denotes an alternative UK-based healthcare trust to those previously mentioned.
} 


\begin{tabular}{|c|c|c|}
\hline Variable & $n$ & $\%$ \\
\hline \multicolumn{3}{|c|}{$\begin{array}{l}\text { View on prevalence of autism on females with ID relative } \\
\text { to males with } \text { ID }^{2}\end{array}$} \\
\hline $\mathrm{F}<<\mathrm{M}(>1: 4)$ & 17 & $21 \%$ \\
\hline $\mathrm{F}<\mathrm{M}(1:<4->2)$ & 36 & $45 \%$ \\
\hline $\mathrm{M}=\mathrm{F}$ (approximately $1: 1)$ & 11 & $14 \%$ \\
\hline $\mathrm{F}>\mathrm{M}(>2-<4: 1)$ & 2 & $3 \%$ \\
\hline $\mathrm{F}>>\mathrm{M}(>4: 1)$ & 0 & - \\
\hline Unsure & 14 & $18 \%$ \\
\hline \multicolumn{3}{|c|}{$\begin{array}{l}\text { Main reason for above view on autism gender ratio in } \\
\text { persons with ID }\end{array}$} \\
\hline Clinical experience & 50 & $63 \%$ \\
\hline Appraisal of research evidence & 21 & $26 \%$ \\
\hline Views of colleagues & 2 & $3 \%$ \\
\hline Multiple reasons contributing equally & 1 & $1 \%$ \\
\hline Other & 1 & $1 \%$ \\
\hline Unsure $^{3}$ & 5 & $6 \%$ \\
\hline \multicolumn{3}{|c|}{$\begin{array}{l}\text { View on prevalence of autism on non-ID females relative } \\
\text { to non-ID males }\end{array}$} \\
\hline $\mathrm{F}<<\mathrm{M}(>1: 4)$ & 12 & $15 \%$ \\
\hline $\mathrm{F}<\mathrm{M}(1:<4->2)$ & 31 & $39 \%$ \\
\hline $\mathrm{M}=\mathrm{F}$ (approximately $1: 1)$ & 11 & $14 \%$ \\
\hline $\mathrm{F}>\mathrm{M}(>2-<4: 1)$ & 1 & $1 \%$ \\
\hline $\mathrm{F}>>\mathrm{M}(>4: 1)$ & 1 & $1 \%$ \\
\hline Unsure & 24 & $30 \%$ \\
\hline \multicolumn{3}{|c|}{$\begin{array}{l}\text { Main reason for above view on autism gender ratio in non- } \\
\text { ID persons }\end{array}$} \\
\hline Clinical experience & 35 & $44 \%$ \\
\hline Appraisal of research evidence & 20 & $25 \%$ \\
\hline Views of colleagues & 6 & $8 \%$ \\
\hline Multiple reasons contributing similarly & 0 & - \\
\hline Other & 3 & $4 \%$ \\
\hline Unsure $^{4}$ & 16 & $20 \%$ \\
\hline \multicolumn{3}{|c|}{$\begin{array}{l}\text { Do you feel that autism manifests differently in females } \\
\text { than in males? }\end{array}$} \\
\hline Yes & 68 & $85 \%$ \\
\hline No & 4 & $5 \%$ \\
\hline Unsure & 8 & $10 \%$ \\
\hline \multicolumn{3}{|c|}{$\begin{array}{l}\text { Main way in which autism manifests differently in } \\
\text { females }^{5}\end{array}$} \\
\hline Ability to mask symptoms & 32 & $40 \%$ \\
\hline Gender-related social expectations & 12 & $15 \%$ \\
\hline Comorbid personality disorder & 6 & $8 \%$ \\
\hline Communication skills & 5 & $6 \%$ \\
\hline Social interaction & 4 & $5 \%$ \\
\hline
\end{tabular}

${ }^{2}$ The ' $<<$ ' or ' $>>$ ' symbols denote 'much less' or 'much greater' respectively, indicating a greater level of difference between genders, whereas the ' $<$ ' or ' $>$ ' symbols denote 'slightly less' or 'slightly more' respectively, indicating a lesser level of difference between genders.

${ }^{3}$ Please note that 9 responders whom said they were 'unsure' regarding the autism gender ratio in persons with ID still provided a main reason for this view (rather than putting 'unsure' in answer to this question as well). ${ }^{4}$ Please note that several responders whom said they were 'unsure' regarding the autism gender ratio in non-ID persons still provided a main reason for this view (rather than putting 'unsure' in answer to this question as well).

${ }^{5}$ Please note that 7 of the 12 responders whom answered either 'No' or 'Unsure' with regards to whether autism manifested differently in females than in males nevertheless provided a main reason in which autism manifests differently in females. 
Emotional and social maturity

Other

Anxiety

Coping skills

Multiple reasons contributing similarly

Routines and resistance to change

Depression

Restricted, stereotyped, repetitive behaviours

Not applicable

Unsure

$\begin{array}{ll}3 & 4 \% \\ 2 & 3 \% \\ 2 & 3 \% \\ 2 & 3 \% \\ 2 & 3 \% \\ 2 & 3 \% \\ 1 & 1 \% \\ 1 & 1 \% \\ 2 & 3 \% \\ 4 & 5 \%\end{array}$




\begin{tabular}{|c|c|c|}
\hline Variable & $n$ & $\%$ \\
\hline \multicolumn{3}{|l|}{$\begin{array}{l}\text { Are you involved in the recognition of patients with possible autism in } \\
\text { your own practice? }\end{array}$} \\
\hline Yes & 62 & $78 \%$ \\
\hline No & 18 & $23 \%$ \\
\hline \multicolumn{3}{|l|}{$\begin{array}{l}\text { As a general rule, what is your level of confidence in recognising } \\
\text { autism in one of your patients? }\end{array}$} \\
\hline Very confident & 14 & $23 \%$ \\
\hline Somewhat confident & 40 & $65 \%$ \\
\hline Neither confident nor unconfident & 7 & $11 \%$ \\
\hline Somewhat unconfident & 1 & $2 \%$ \\
\hline Very unconfident & 0 & - \\
\hline Not applicable ${ }^{6}$ & 18 & - \\
\hline \multicolumn{3}{|l|}{$\begin{array}{l}\text { As a general rule, what is your level of confidence in recognising } \\
\text { autism in your female patients, compared to your male patients? }\end{array}$} \\
\hline Much more confident & 1 & $2 \%$ \\
\hline Somewhat more confident & 0 & - \\
\hline As confident & 30 & $48 \%$ \\
\hline Somewhat less confident & 29 & $47 \%$ \\
\hline Much less confident & 1 & $2 \%$ \\
\hline Not applicable (but reported being involved in recognition of autism) & 1 & $2 \%$ \\
\hline Not applicable (and not involved in recognition of autism) ${ }^{7}$ & 18 & - \\
\hline \multicolumn{3}{|l|}{$\begin{array}{l}\text { Are you involved in the screening of patients with possible autism in } \\
\text { your own practice? }\end{array}$} \\
\hline Yes & 31 & $39 \%$ \\
\hline No & 49 & $61 \%$ \\
\hline \multicolumn{3}{|l|}{$\begin{array}{l}\text { If you are involved in the screening of patients with possible autism, } \\
\text { which of the following tools do you use? }\end{array}$} \\
\hline Autism Quotient (AQ) (Baron-Cohen et al., 2001) & 17 & $55 \%$ \\
\hline $\begin{array}{l}\text { Ritvo Autism Asperger Diagnostic Scale - Revised (RAADS-R) (Ritvo et } \\
\text { al., 2011) }\end{array}$ & 1 & $3 \%$ \\
\hline Social Responsiveness Scale (SRS) (Constantino and Gruber, 2012) & 3 & $10 \%$ \\
\hline Clinical/professional judgment & 25 & $81 \%$ \\
\hline Other & 12 & $39 \%$ \\
\hline \multicolumn{3}{|l|}{$\begin{array}{l}\text { As a general rule, what is your level of confidence in screening for } \\
\text { autism in one of your patients? }\end{array}$} \\
\hline Very confident & 6 & $19 \%$ \\
\hline Somewhat confident & 22 & $71 \%$ \\
\hline Neither confident nor unconfident & 1 & $3 \%$ \\
\hline Somewhat unconfident & 2 & $6 \%$ \\
\hline Very unconfident & 0 & - \\
\hline Not applicable $^{9}$ & 49 & - \\
\hline
\end{tabular}

${ }^{6} 9$ of the 18 (9/18) responders whom reported not being involved in the recognition of patients with possible autism in their own practice still provided an answer pertaining to their level of confidence in recognising autism in one of their patients. For the purposes of this study, these results were categorised as being 'not applicable.'

${ }^{7} 11 / 18$ responders whom reported not being involved in the recognition of patients with possible autism in their own practice still provided an answer pertaining to their level of confidence in recognising autism in their female patients, compared to their male patients; such answers were categorised as being 'not applicable.' ${ }^{8}$ Responders are able to give multiple answers for this question, thus resulting percentage values add up to $>100 \%$. Additionally, 2/49 responders whom reported not being involved in the screening of patients with possible autism in their own practice still provided an answer regarding the screening tools they used; such answers were categorised as being 'not applicable.'

${ }^{9} 18 / 49$ responders whom reported not being involved in the screening of patients with possible autism in their own practice still provided an answer pertaining to their level of confidence in screening for autism in one of their patients; such answers were categorised as being 'not applicable.' 
As a general rule, what is your level of confidence in screening for autism in your female patients, compared to your male patients?

Much more confident

Somewhat more confident

As confident

Somewhat less confident

Much less confident

Not applicable ${ }^{10}$

Do you conduct full autism diagnostic assessments in your own clinical practice?

Yes

No

$21 \%$

If yes to above, how frequently do you typically conduct such assessments?

$>1$ per month

1 per month

1 every 3 months

1 every 6 months

1 every 9 months

1 every 12 months

$<1$ every 12 months

No answer provided

Not applicable

Have you received any formal training for autism diagnosis?

Yes

No

If yes to above, what training have you received? ${ }^{11}$

Adult Asperger Assessment (AAA) (Baron-Cohen et al., 2005b)

Asperger Syndrome Diagnostic Interview (ASDI) (Gillberg et al., 2001)

Autism Diagnostic Interview - Revised (ADI-R) (Lord et al., 1994)

Autism Diagnostic Observation Schedule (ADOS) (Lord et al., 2000)

Diagnostic Interview for Social and Communication Disorders (DISCO)

(Wing et al., 2002)

Ritvo Autism Asperger Diagnostic Scale - Revised (RAADS-R) (Ritvo et al., 2011)

Other

Not applicable

As a general rule, what is your level of confidence in diagnosing autism in one of your patients?

Very confident

Somewhat confident

Neither confident nor unconfident

Somewhat unconfident

Very unconfident

Not applicable (respondents whom selected 'not applicable' with as their answer despite conducting autism diagnostic assessments in their own clinical practice)

Not applicable (due to not conducting such assessments in their own clinical practice $)^{12}$

\footnotetext{
${ }^{10} 19 / 49$ responders whom reported not being involved in the screening of patients with possible autism in their own practice still provided an answer pertaining to their level of confidence in screening for autism in their female patients, compared to their male patients; such answers were categorised as being 'not applicable.'

${ }^{11}$ Responders are able to give multiple answers for this question, thus resulting percentage values add up to $>100 \%$.

$1232 / 63$ responders whom reported not conducting full autism diagnostic assessments in their own practice still provided an answer pertaining to their level of confidence in diagnosing autism in one of their patients; such answers were categorised as being 'not applicable.'
} 
Table 4: Views on autism-related training needs

\begin{tabular}{|lcc|}
\hline Variable & $\boldsymbol{n}$ & $\mathbf{\%}$ \\
\hline $\begin{array}{l}\text { Do you feel that you have any additional training needs regarding } \\
\text { care provision for patients with autism? }\end{array}$ & & \\
Yes & 61 & $76 \%$ \\
No & 19 & $24 \%$ \\
Which of the above do you feel is the most important training need for & & \\
you? & 3 & $5 \%$ \\
Autism in different minority ethnic groups & 4 & $7 \%$ \\
Autism in mild-moderate intellectual disability & 2 & $3 \%$ \\
Autism in moderate-severe intellectual disability & 4 & $7 \%$ \\
Family and carer interventions & 7 & $11 \%$ \\
Gender differences in autism & 8 & $13 \%$ \\
Identification and diagnosis & 10 & $16 \%$ \\
Interventions for autism & 5 & $8 \%$ \\
Interventions for challenging behaviour & 5 & $8 \%$ \\
Interventions for coexisting mental disorders & 10 & $16 \%$ \\
Sensory needs & 1 & $2 \%$ \\
Multiple training needs of equal importance & 2 & $3 \%$ \\
No answer provided & 19 & - \\
Not applicable ${ }^{13}$ & & \\
\hline
\end{tabular}

13 3/19 responders whom reported not having any additional training needs still provided an answer pertaining to their most important training need; these answers were categorised as being 'not applicable.' 